\title{
Article \\ Rheological and Chemical Evolution of HMA and WMA Binders Based on Ageing Kinetics
}

\author{
Ao Huang ${ }^{1}$, Gang Liu ${ }^{1, *}$, Virginie Mouillet ${ }^{2, *}\left(\mathbb{D}\right.$, Saannibe Ciryle Somé ${ }^{3}\left(\mathbb{D}\right.$, Tingwei Cao ${ }^{1}$ and Haoliang Huang ${ }^{4}$ \\ 1 State Key Laboratory of Silicate Materials for Architectures, School of Materials Science and Engineering, \\ Wuhan University of Technology, Wuhan 430070, China; ha@whut.edu.cn (A.H.); ctw-123@163.com (T.C.) \\ 2 Cerema, Research Team DIMA, CEDEX 3, 13593 Aix-en-Provence, France \\ 3 Cerema, Research Team DIMA, 77171 Sourdun, France; ciryle.some@cerema.fr \\ 4 School of Materials Science and Engineering, South China University of Technology, \\ Guangzhou 510000, China; huanghaoliang@scut.edu.cn \\ * Correspondence: liug@whut.edu.cn (G.L.); virginie.mouillet@cerema.fr (V.M.); \\ Tel.: +86-15-827-281-221 (G.L.); +33-442-24-78-27 (V.M.)
}

check for updates

Citation: Huang, A.; Liu, G.;

Mouillet, V.; Somé, S.C.; Cao, T.; Huang, H. Rheological and Chemical Evolution of HMA and WMA Binders Based on Ageing Kinetics. Materials 2022, 15, 679. https:// doi.org/10.3390/ma15020679

Academic Editors: Hussain Bahia, Sandra Erkens, Yue Hou, Xueyan Liu and Yue Xiao

Received: 1 December 2021

Accepted: 12 January 2022

Published: 17 January 2022

Publisher's Note: MDPI stays neutral with regard to jurisdictional claims in published maps and institutional affiliations.

Copyright: (c) 2022 by the authors. Licensee MDPI, Basel, Switzerland. This article is an open access article distributed under the terms and conditions of the Creative Commons Attribution (CC BY) license (https:// creativecommons.org/licenses/by/ $4.0 /)$.

\begin{abstract}
It is fundamental to predict or estimate the rheological behavioural evolutions of binders and mixture to ensure a durability service life of the whole infrastructure. This study compared the long-term ageing kinetics of hot mix asphalt (HMA) and warm mix asphalt (WMA) produced with the same base bitumen. The difference in the component was that the WMA contained $1 \%$ of Cecabase warm agent and $5.5 \%$ of water by the weight of bitumen, to obtain a large expansion ratio (47 times). Rolling thin-film oven test (RTFOT) and pressure ageing vessel (PAV) laboratory ageing were carried out on the binder with or without the warm agent. The oven ageing procedure was conducted on the loose HMA and WMA mixtures for 0, 3, 6, and 9 days. Research results indicated that the dual effect of the studied warm agent and the foaming water sharply decreased the viscosity of the binder at a high temperature. Compared with the HMA, the warm agent improved the ageing resistance of the asphalt binder. However, higher content, such as $5.5 \mathrm{wt} . \%$, of foaming water deteriorated viscosity due to a thinner bitumen film, which was more susceptible to oxidation. Therefore, less than $2 \mathrm{wt} . \%$ of warm agent and foaming water was recommended in the foamed WMA preparation.
\end{abstract}

Keywords: bitumen; warm agent; foaming; ageing; rheology

\section{Introduction}

Warm mix asphalt has a paving temperature of $100-140{ }^{\circ} \mathrm{C}$, lower by $20-40{ }^{\circ} \mathrm{C}$ than that of traditional hot mix asphalt (HMA) [1]. Compared with HMA, WMA can reduce $\mathrm{CO}_{2}$ emissions by an average of $67 \%$ [2] and save energy by about $30 \%$ [3]. There are three main methods to produce WMA by using (i) organic additives, (ii) chemical additives, and (iii) foaming techniques [4]. Wax or fatty amides are usually used as organic additives to reduce the viscosity of asphalt binder [5]. Chemical additives are usually a combination of emulsifiers or surfactants to help asphalt binder covers aggregate at a lower temperature [6]. In the foaming technique, the addition of water into the hot bitumen causes steam to entrap and generates a large volume of foam, which temporarily increases the volume of the asphalt binder and reduces mix viscosity [4].

The effect of each warm agent on asphalt binder property is different. Aspha-min and Sasobit agents improved the rutting resistance and crack resistance of binders but had no significant effect on fatigue performance [7]. Xiao indicated that the four types of WMA agents (Cecabase, Evotherm, Rediset, and Sasobit) after the RTFOT ageing still maintained viscoelastic properties of the binder [8]. Compared with the organic additives, the chemical additives were less affected by oxidative ageing [9]. The chemical additive Cecabase increased the stiffness of the binder by 1.3 times and imparted the WMA with more than $80 \%$ ability of HMA's to resist the moisture damage [10]. Non-foaming additives demonstrated 
better ageing indices than foaming additives, and the chemical WMA additive exhibited better performance, compared with organic additives [11].

The water-based foaming techniques had excellent cost effectiveness and were the most widely used [12]. The binder foamed by $2 \%$ water exhibited a better ageing resistance for the short term but not for the long term [13]. The laboratory-prepared foamed WMA mixtures with $1.8 \%$ water underwent comparable or slightly lower levels of ageing, compared with traditional HMA mixtures [14]. It was indicated that the water content influenced the ageing properties of foamed WMA. The combination of chemical and foaming technology was also used to lower the construction temperature of the HMA. Firstly, a chemical additive was added into the hot coarse aggregates, and then, the wet sand was added to create a foaming action [15].

HMA and WMA consist of aggregates, bitumen, filler, and additives [16]. Their global mechanical performances entirely depend on their component's percentage, the properties with the time evolution, and their interaction with each other [17]. During the design phase of the mixtures, it is fundamental to predict or at least estimate the evolution of rheological behaviours of binders and mixes to ensure the durability of the whole infrastructure [18]. In particular, WMA has more complex components, its mixing and paving temperatures are different from those of HMA, and its ageing protocols are still under investigation [19].

This study addresses the long-term ageing kinetic comparison of HMA and WMA manufactured with the same base bitumen. The results can be used to discriminate the ageing behaviour of WMA, compared with HMA. The paper focuses on analysing the evolution of physicochemical and rheological parameters of binders and mixes according to the long-term ageing kinetics. It also allows a reasonable ageing protocol to be proposed for foamed WMA, by comparing the RILEM ageing protocol on loose mixes following CEN TS 12697-52 and the rolling thin-film oven test (RTFOT), plus the pressure ageing vessel (PAV) method on bitumen following the EN 12607-1 and the EN 14769 developed for HMA.

\section{Materials and Methods}

\subsection{Materials}

The virgin binder was a paving grade bitumen 50/70 defined according to the European standard (EN 12591). It was provided by Nynas company (Stockholm, Sweden) and called Nyfoam since it was suitable to produce foam mix asphalt. It had a needle penetration value of $57 \times 0.1 \mathrm{~mm}$ and a softening temperature of $49.6^{\circ} \mathrm{C}$ according to EN 1426 and EN 1427.

Porphyry aggregates from Pont de Colonne Quarry (Côte-d'Or, France), were used. It had a Los Angeles abrasion loss (EN 1097-2) and microDeval fragmentation (EN 1097-1) of $17 \%$ and $8 \%$, respectively.

Following the EN 13108-1, the hot mixture AC10 (HMA) was prepared with an optimum binder content of $5.4 \%$ at $165{ }^{\circ} \mathrm{C}$. This mixture was mainly used for surface and binder courses of the pavement [20]. The Wirtgen WBL 10S (Wirtgen, Windhagen, Germany) equipment was employed to produce the foamed WMA at $135^{\circ} \mathrm{C}$. Compared with the HMA, the difference in the component was that the WMA contained 1\% of Cecabase warm agent and $5.5 \%$ of water by the weight of bitumen, to obtain the maximum expansion ratio of the foam equal to 47 times of the initial bitumen volume.

\subsection{The Ageing Process}

RTFOT and PAV were used to simulate the short-term and the long-term ageing on asphalt binder, respectively. The related norms were EN 12607-1 and EN 14769. The WMA binder was prepared by mixing the base binder with $1 \mathrm{wt} . \%$ of the warm agent at $160{ }^{\circ} \mathrm{C}$ for $15 \mathrm{~min}$. The RTFOT was performed on the WMA binder at $140{ }^{\circ} \mathrm{C}$. Other parameters remained the same for the HMA binder according to the norms.

The ageing protocol was performed on a loose asphalt mixture since it provided more explosion to the air which accelerated ageing, and meanwhile, the resulting ageing on the mixture was more homogeneous. After the mixing, the loose HMA mixture was cooled 
down from $165{ }^{\circ} \mathrm{C}$ to $135^{\circ} \mathrm{C}$ and then spread in a tray with a thickness of around $2.5 \mathrm{~cm}$. Then, the tray was placed in a ventilated oven for $4 \mathrm{~h}$, to simulate the short-term ageing. Next, it was cooled down to $85^{\circ} \mathrm{C}$ and kept in the oven for 3, 6, and 9 days, to simulate the long-term ageing. The WMA mixture was manufactured at $135{ }^{\circ} \mathrm{C}$ by the Wirtgen WBL $10 \mathrm{~S}$ equipment and then immediately spread in the tray following the same short-term and long-term ageing procedure similar to the procedure performed on the HMA mixture. The ageing protocols on the HMA and WMA mixtures are illustrated in Figure 1, and the codes for the aged binder samples are given in Table 1.

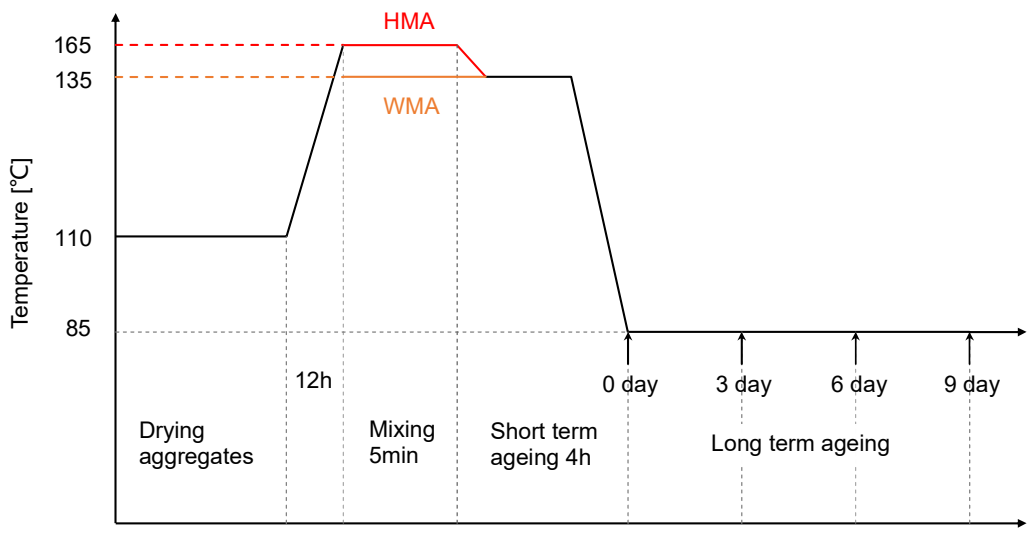

Figure 1. The illustration on the ageing protocols for the HMA and WMA mixtures.

Table 1. Codes for the binder samples before and after ageing.

\begin{tabular}{|c|c|c|}
\hline Binder Group & Binder Code & Items \\
\hline \multirow{3}{*}{ Group 1} & Virgin HMA & Virgin Nyfoam binder \\
\hline & RTFO HMA & after RTFOT at $163^{\circ} \mathrm{C}$ \\
\hline & PAV HMA & after RTFOT at $163^{\circ} \mathrm{C}+20 \mathrm{~h}$ PAV \\
\hline \multirow{3}{*}{ Group 2} & Fresh WMA & Virgin Nyfoam binder + 1\% warm agent \\
\hline & RTFO WMA & Fresh WMA binder after RTFOT at $140^{\circ} \mathrm{C}$ \\
\hline & PAV WMA & Fresh WMA binder after RTFOT at $140^{\circ} \mathrm{C}+20 \mathrm{~h}$ PAV \\
\hline \multirow{4}{*}{ Group 3} & 0-day HMA & Recovered from the loose HMA mixture \\
\hline & 3-day HMA & Recovered from the HMA mixture after 3-day oven ageing \\
\hline & 6-day HMA & Recovered from the HMA mixture after 6-day oven ageing \\
\hline & 9-day HMA & Recovered from the HMA mixture after 9-day oven ageing \\
\hline \multirow{4}{*}{ Group 4} & 0-day WMA & Recovered from the loose WMA mixture \\
\hline & 3-day WMA & Recovered from the WMA mixture after 3-day oven ageing \\
\hline & 6-day WMA & Recovered from the WMA mixture after 6-day oven ageing \\
\hline & 9-day WMA & Recovered from the WMA mixture after 9-day oven ageing \\
\hline
\end{tabular}

\subsection{Bituminous Binders Recovery}

Binder extraction was performed according to the European standard NF EN 12697-3, and it was based on the dissolution in the dichloromethane solvent at room temperature. The obtained binder solution was then filtered and centrifuged to remove all aggregate particles from the binder solution. Afterwards, the solvent was removed by distillation under an air vacuum. It is important to note that after the binder was extracted and recovered, it was analysed by infrared spectroscopy to ensure complete solvent removal (no infrared peaks of chlorine), and the calcination residue during $8 \mathrm{~h}$ at $450{ }^{\circ} \mathrm{C}$ has to be less than $1 \%$ of binder test portion. After complete solvent removal, physicochemical and rheological studies were performed on recovered binders, aged at different levels from 0 to 9 days. 


\subsection{Testing Methods}

Figure 2 presents the detailed investigation program employed in this study to characterise the rheological and chemical evolution of both WMA and HMA binder based on ageing kinetics. Viscosity, DSR, FTIR, and GPC analyses were conducted for fundamental study on the slow ageing evolution of asphalt binder in the warm mix and hot mix, by means of both chemical study and mechanic test.

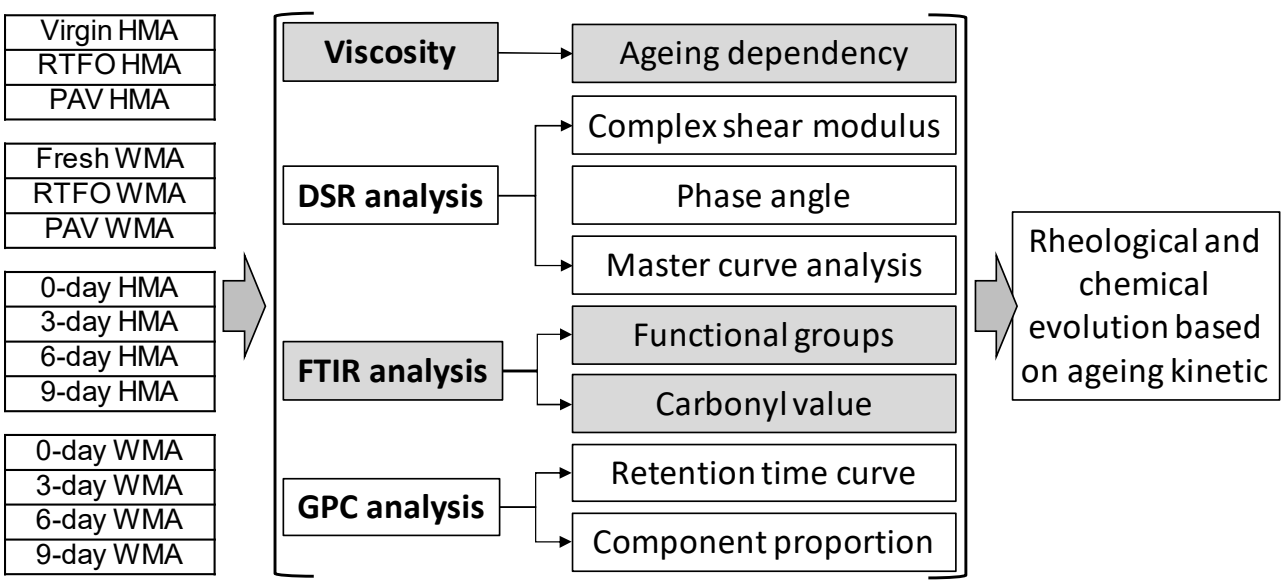

Figure 2. Detailed research program for rheological and chemical evolution study.

The dynamic shear rheometer (DSR), with the help of Anton Paar Smart Pave 102 (Graz, Austria), was adopted to characterise the complex modulus and phase angle of the asphalt binder. The test was performed at $20,25,30,40,50$, and $60^{\circ} \mathrm{C}$, using the parallel plates with a diameter of $25 \mathrm{~mm}$ with a gap of $2 \mathrm{~mm}$. Before starting the DSR measurement, strain sweeps were performed to determine the linear viscoelastic region of the binder. The WLF equation (WLF = William, Landel, and Ferry) was used to calculate the shift factors to construct master curves.

A cone/plate rheometer, with a cone angle of $1^{\circ}$ and plate diameter of $25 \mathrm{~mm}$ installed on the DSR, was used to characterise the viscosity as a function of the shear rate. A shear rate sweep from $0.001 \mathrm{~s}^{-1}$ to $10 \mathrm{~s}^{-1}$ at $60^{\circ} \mathrm{C}$ and $0.1 \mathrm{~s}^{-1}$ to $1000 \mathrm{~s}^{-1}$ at $120{ }^{\circ} \mathrm{C}$ was performed.

A Thermo Scientific Nicolet 6700 Fourier Transform Infrared (FTIR) spectrometer (Thermo Fisher Scientific, Waltham, MA, USA) was used to characterise the chemical information of the binder at a middle infrared region of $2000 \sim 500 \mathrm{~cm}^{-1}$. Firstly, $0.1 \mathrm{~g}$ bitumen was dissolved in $2 \mathrm{~mL}$ carbon disulphide; next, the solution was applied on the $\mathrm{KBr}$ sheet; Finally, a Na lamp was used to dry the sheet. A carbonyl index (CI) was used to characterise the ageing degree quantitatively, and it was defined as

$$
\mathrm{CI}=\mathrm{A}_{1720-1678} / \mathrm{A}_{1400-700}
$$

where $A_{1720-1678}$ is the carbonyl area in the range of $1720-1678 \mathrm{~cm}^{-1}$, and $A_{1400-700}$ the fingerprint area in the field of $1400-700 \mathrm{~cm}^{-1}$.

Gel permeation chromatography (GPC) was used to analyse the molecular weight distribution of virgin and aged binders [21]. The Agilent PL-GPC50 equipment (Santa Clara, CA, USA) was used with a chromatographic column of Agilent MIXED-C columns and a constant temperature of $40^{\circ} \mathrm{C}$. Testing parameters are given in Table 2 . 
Table 2. GPC test conditions for bitumen.

\begin{tabular}{cc}
\hline Items & Content \\
\hline Mobile phase & Tetrahydrofuran (THF) \\
Solvent (sample preparation) & THF $(30 \mathrm{~min}, 100 \mathrm{rpm}$ at room temperature) \\
Sample concentration & $0.10 \mathrm{mg} / \mathrm{mL}$ \\
Injection volume & $100 \mu \mathrm{L}$ \\
Flow rate & $1.5 \mathrm{~mL} / \mathrm{min}$ \\
Test temperature & $40^{\circ} \mathrm{C}$ \\
Detector & Photodiode Array, (PDA) \\
Columns & Agilent PLgel $5 \mu$ miXED-C columns \\
Calibration standards & Polystyrene \\
\hline
\end{tabular}

Based on the GPC results, bituminous molecules were divided into three types with a small molecular size (SMS), a medium molecular size (MMS), and a large molecular size (LMS), which are illustrated in Figure 3. The area of LMS, MMS, and SMS underneath the GPC curve represented the related quantity and was calculated for further study.

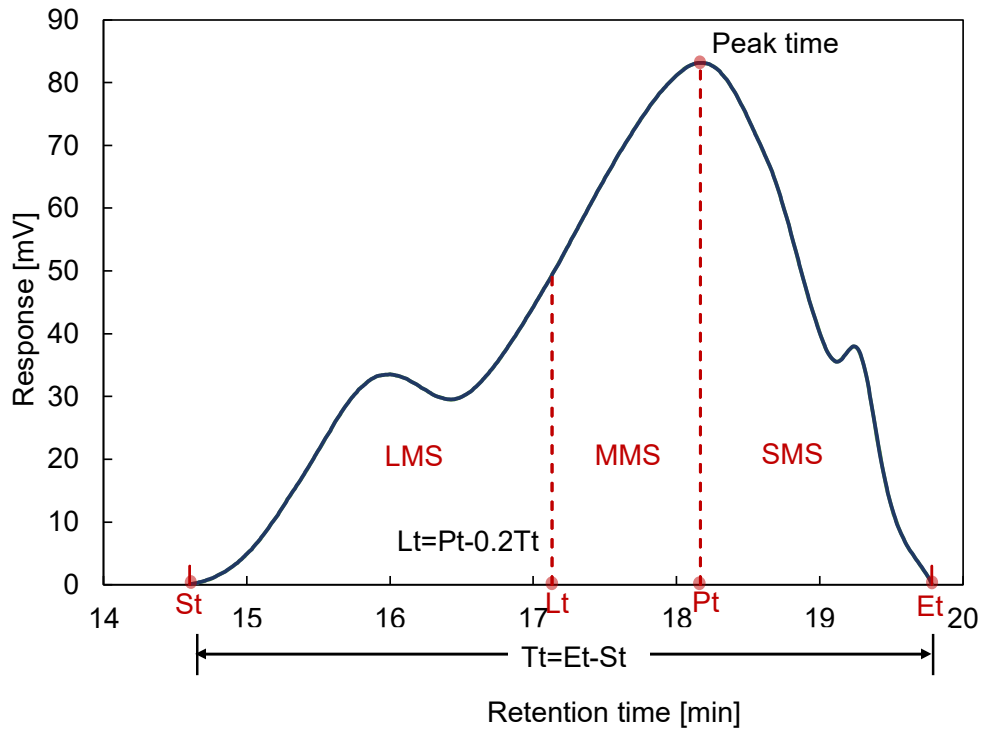

Figure 3. Illustration of determining LMS time (Lt) from total retention time (Tt) of the chromatogram of virgin binder (asphalt A), based on ending time (Et) and starting time (St) [22].

The IATROSCAN MK-6S rod thin layer chromatography (NTS America, Inc., Brooklyn, NY, USA) was adopted to determine four components of binder in this study [23]. First, the bitumen/dichloromethane solution was configured with a mass concentration of $20 \mathrm{mg} / \mathrm{mL}$. Next, a micro-syringe was used to transfer $50 \mu \mathrm{L}$ of the solution to the origin of the silica gel chromatographic rod and place it in the cylinder at a constant temperature to dry. Finally, four components were separated as follows:

(1) The n-heptane was used, to expand the four components in the rod to the chromatographic bar scale of 100 , and dried at $80^{\circ} \mathrm{C}$ for $1 \mathrm{~min}$;

(2) A mixed solvent of toluene and n-heptane (volume ratio 1:1) was used, to expand the components to the chromatographic bar scale of 50 , and dried at $80^{\circ} \mathrm{C}$ for another 1 min;

(3) The mixed solvent of toluene and ethanol (volume ratio 1:1) was used, to expand the components to the chromatographic bar scale of 25 , and dried at $80^{\circ} \mathrm{C}$ for $1 \mathrm{~min}$;

(4) Finally, the rod was placed in hydrogen flame condition at a constant speed to measure the weight of the four individual components. 


\section{Results}

\subsection{Viscosity}

With the shear rate ranging from $0.001 \mathrm{~s}^{-1}$ to $1 \mathrm{~s}^{-1}$, a Newtonian plateau was observed for all binders, and their zero-shear viscosity was obtained. In comparison, the zero-shear viscosity of fresh WMA binder was lower than the virgin HMA binder, due to the addition of a warm agent. The zero-shear viscosities of 0-day HMA and 0-day WMA binders were very close and higher than that of virgin HMA. This means that ageing occurred while producing the HMA and WMA mixtures. When the shear rate was higher than $1 \mathrm{~s}^{-1}$, the shear-thinning behaviour was observed and was more evident for aged binders, such as PAV HMA, PAV WMA (Figure 4a), 3-day WMA, and 6-day WMA binders (Figure 4b). Shear thinning occurs because the macromolecule chains usually exist in a state of random orientation and high entanglement, and they will become disentangled and oriented at high shear rates. It was revealed that ageing increased the content of macromolecules in the bitumen.

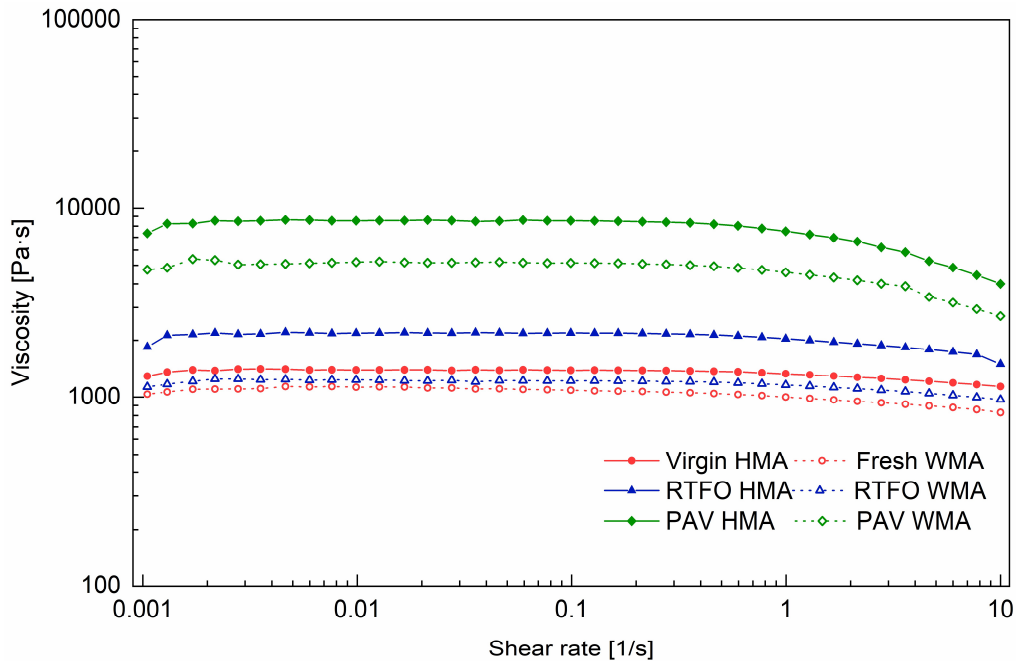

(a)

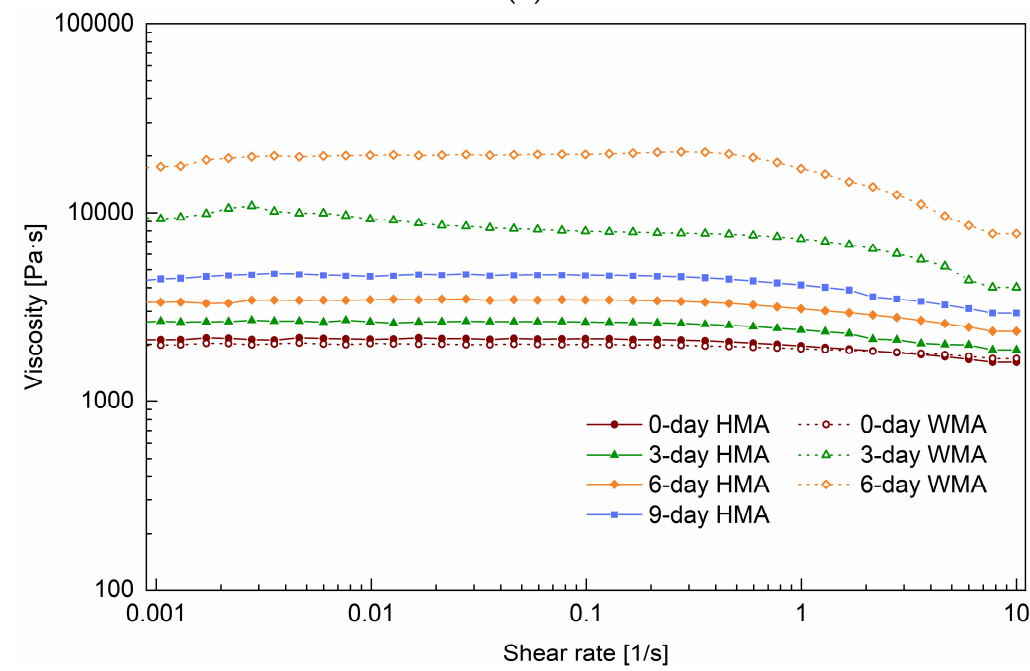

(b)

Figure 4. Shear rate dependency of viscosity of the binders at $60^{\circ} \mathrm{C}$ before and after ageing: (a) for groups 1, 2, and (b) for groups 3 and 4 .

Figure 5 shows the shear rate dependency of viscosity of the studied binders at $120{ }^{\circ} \mathrm{C}$ before and after ageing. Different from the curve at $60^{\circ} \mathrm{C}$, a shear thinning of the bitumen started at a low shear rate, and a Newtonian plateau was reached above $10 \mathrm{~s}^{-1}$. The shear 
thinning for binder groups 1 and 2 (Figure 5a) was more obvious than that for binder groups 3 and 4 (see Figure $5 \mathrm{~b}$ ) between the shear rates of $0.1 \mathrm{~s}^{-1}$ and $10 \mathrm{~s}^{-1}$. The reason could be that the extraction process with asphalt mixture made the bituminous molecules more oriented [24]. The ageing conditions on the binder and mixture could be another reason to cause the differences in this behaviour.

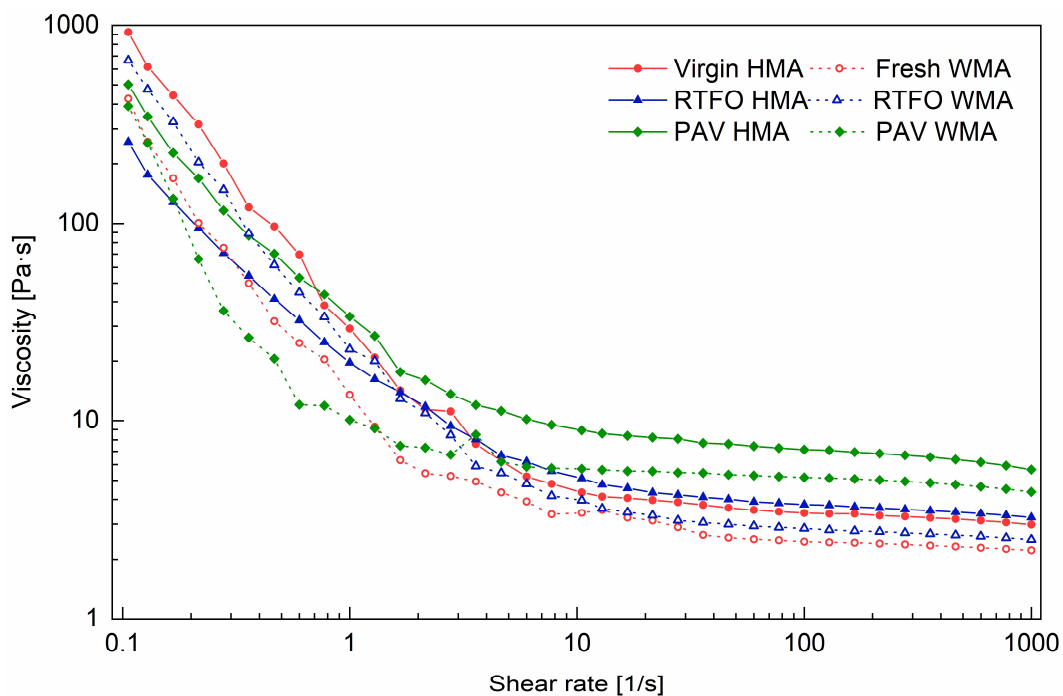

(a)

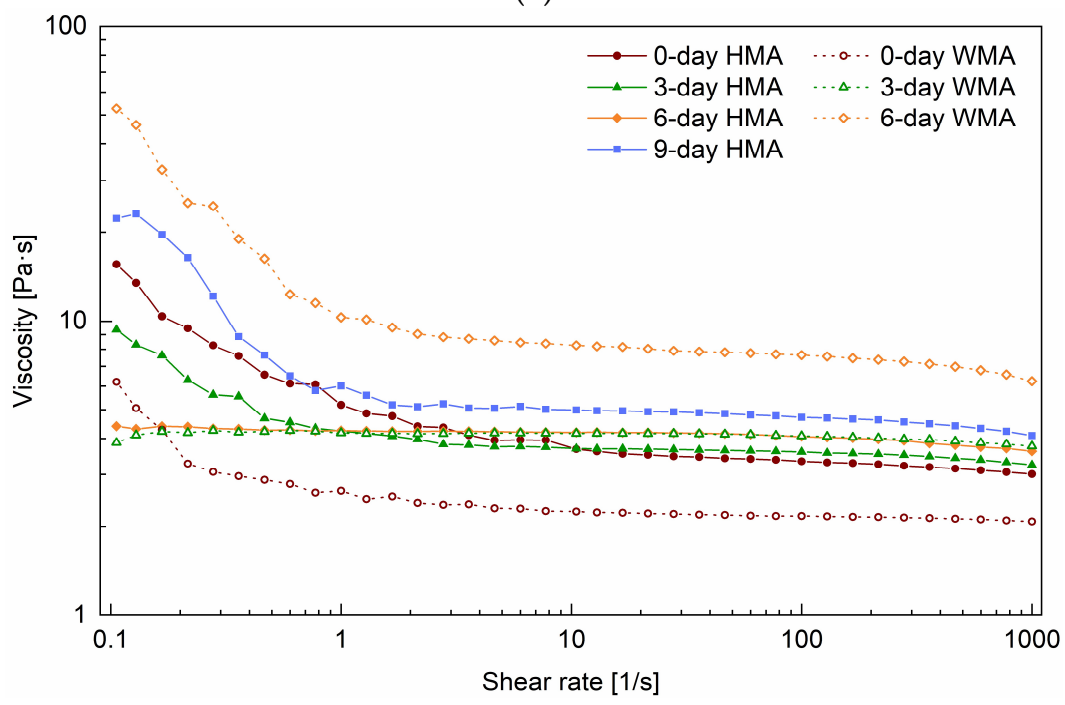

(b)

Figure 5. Shear rate dependency of viscosity of the binders at $120^{\circ} \mathrm{C}$ before and after ageing: (a) for groups 1, 2, and (b) for groups 3 and 4 .

Table 3 lists the viscosity of binders at $60{ }^{\circ} \mathrm{C}$ and $120^{\circ} \mathrm{C}$. The viscosity at the corresponding shear rates belonged to the Newtonian plateau and can reflect the intrinsic behaviour of the asphalt binder. The viscosity of $2.18 \mathrm{~Pa} \cdot \mathrm{s}$ for 0-day WMA binder was less than 3.33 Pa.s for 0-day HMA binder. With the addition of a warm agent, the ageing resistance of the binder was improved. Compared with the virgin HMA binder, the PAV WMA binder had a viscosity of $5.17 \mathrm{~Pa} \cdot \mathrm{s}$ less than $7.15 \mathrm{~Pa} \cdot \mathrm{s}$ for the PAV HMA binder. However, the 6-day WMA had a viscosity of $7.63 \mathrm{~Pa} \cdot \mathrm{s}$, much higher than $4.06 \mathrm{~Pa} \cdot \mathrm{s}$ for the 6-day HMA binder. The reason could be that the addition of water accelerated the ageing of the mixture whose film thickness was thinner than the mixture aged in RTFOT and PAV. The viscosity of the 9-day WMA was too high to be measured. 
Table 3. Viscosity of all binders at $60^{\circ} \mathrm{C}$ and $120^{\circ} \mathrm{C}$.

\begin{tabular}{|c|c|c|c|}
\hline \multicolumn{2}{|c|}{ Binder Groups } & $\begin{array}{c}\text { Viscosity } \\
\text { at } 60^{\circ} \mathrm{C} \text { and } 1 \mathrm{~s}^{-1}(\mathrm{~Pa} \cdot \mathrm{s})\end{array}$ & $\begin{array}{c}\text { Viscosity } \\
\text { at } 120{ }^{\circ} \mathrm{C} \text { and } 100 \mathrm{~s}^{-1}(\mathrm{~Pa} \cdot \mathrm{s})\end{array}$ \\
\hline \multirow{3}{*}{ Group 1} & Virgin HMA & 1337.4 & 3.42 \\
\hline & RTFO HMA & 2035.20 & 3.77 \\
\hline & PAV HMA & 7524.70 & 7.15 \\
\hline \multirow{3}{*}{ Group 2} & Fresh WMA & 1000.80 & 2.45 \\
\hline & RTFO WMA & 1163.60 & 2.85 \\
\hline & PAV WMA & 4596.00 & 5.17 \\
\hline \multirow{4}{*}{ Group 3} & 0-day HMA & 1994.20 & 3.33 \\
\hline & 3-day HMA & 2426.70 & 3.59 \\
\hline & 6-day HMA & 3171.10 & 4.06 \\
\hline & 9-day HMA & 4222.80 & 4.71 \\
\hline \multirow{3}{*}{ Group 4} & 0-day WMA & 1912.80 & 2.18 \\
\hline & 3-day WMA & 7415.10 & 4.08 \\
\hline & 6-day WMA & 18445.00 & 7.63 \\
\hline
\end{tabular}

\subsection{Viscoelastic Properties}

For the binders shown in Figure 6, a general observation was that the complex modulus of the binders converged at the high-frequency region, and the phase angle converged at the low-frequency area. Due to the addition of the warm agent, the fresh WMA binder had a slightly lower complex modulus and a higher phase angle than the Virgin HMA binder (Figure 6a). In comparison, the modulus master curve of the PAV WMA binder was located below that of the PAV HMA binder. This means that the warm agent used in this study improved the ageing resistance of the virgin binder.

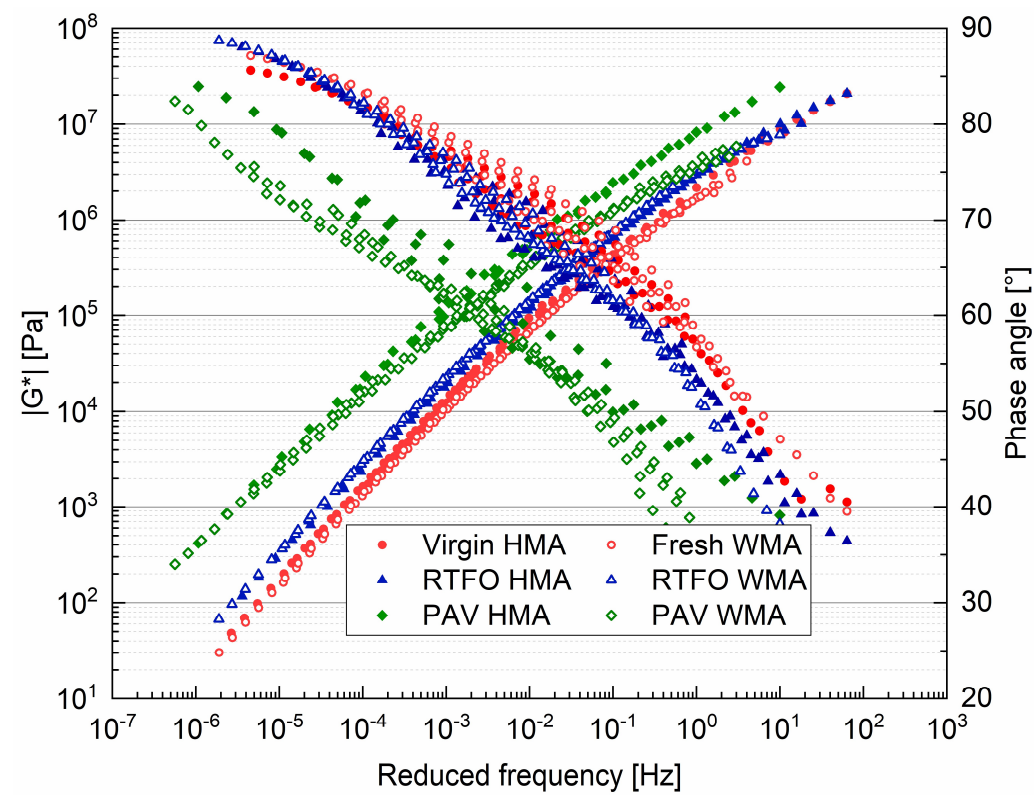

(a)

Figure 6. Cont. 


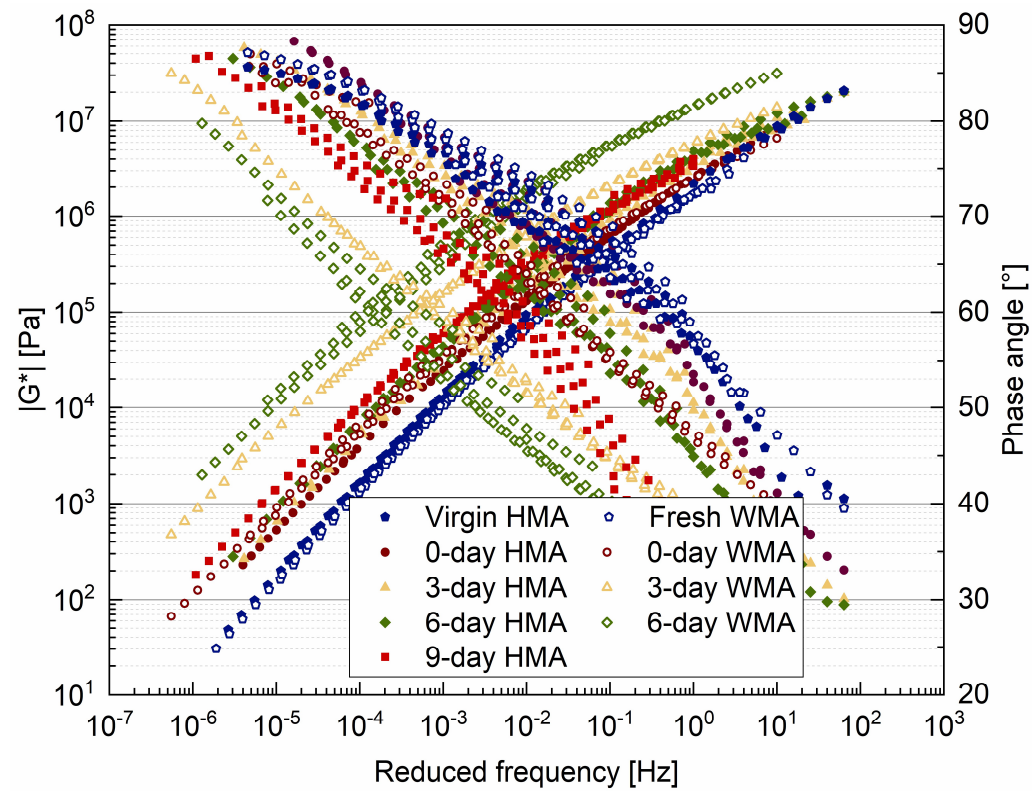

(b)

Figure 6. Master curve of (a) HMA binders and (b) WMA binders before and after ageing. Ascending curves represent complex moduli $\left|\mathrm{G}^{*}\right|$ while descending curves represent the phase angle.

As shown in Figure 6b, the modulus master curve of the 0-day HMA binder was located above that of the virgin HMA binder due to short-term ageing, as illustrated in Figure 1. The complex modulus of binders gradually increased with ageing time. The complex modulus of the 0-day WMA binder was very close to that of the 6-day HMA. It was found that the binder in the WMA mixture quickly aged in the oven. The 6-day WMA binder had the highest complex modulus and the lowest phase angle. The 9-day WMA binder was too hard to undergo experiment by the frequency sweep.

Typically, water content less than $2 \%$ by the weight of binder was used in the foam asphalt mixture. Previous research indicated that a water content higher than $2 \%$ accelerated the ageing of the binder [25]. The high water content of 5.5\% caused a large expansion ratio (47 times). Then, it made the bitumen film thinner and more susceptible to oxidation. Another point worth noting is that the positive effect of warm mixes on the long-term performance of asphalt was no longer present.

\subsection{FTIR}

As shown in Figure 7, FTIR was used to evaluate the ageing behaviour of HMA and WMA binders. Typical peaks were observed, such as in-plane bending vibration of the $-\mathrm{OH}$ groups at $1627 \mathrm{~cm}^{-1}$ and the scissoring vibration of $-\mathrm{CH}_{2}$ at $1464 \mathrm{~cm}^{-1}$. There was no specific characteristic peak for the warm agent when comparing fresh WMA and virgin HMA binders. Two critical functional groups were characterised by the FTIR spectra. One was the carbonyl group at $1700 \mathrm{~cm}^{-1}$, and another was the sulphoxide group at $1030 \mathrm{~cm}^{-1}$. Both belong to the stretching vibration and are formed due to the oxidation, dehydrogenation, and crosslinking reactions occurring simultaneously. The carbonyl group was more sensitive to ageing in this study, and its band became broader as ageing proceeded. Therefore, the CI value was used to characterise the ageing degree semi-quantitatively. 


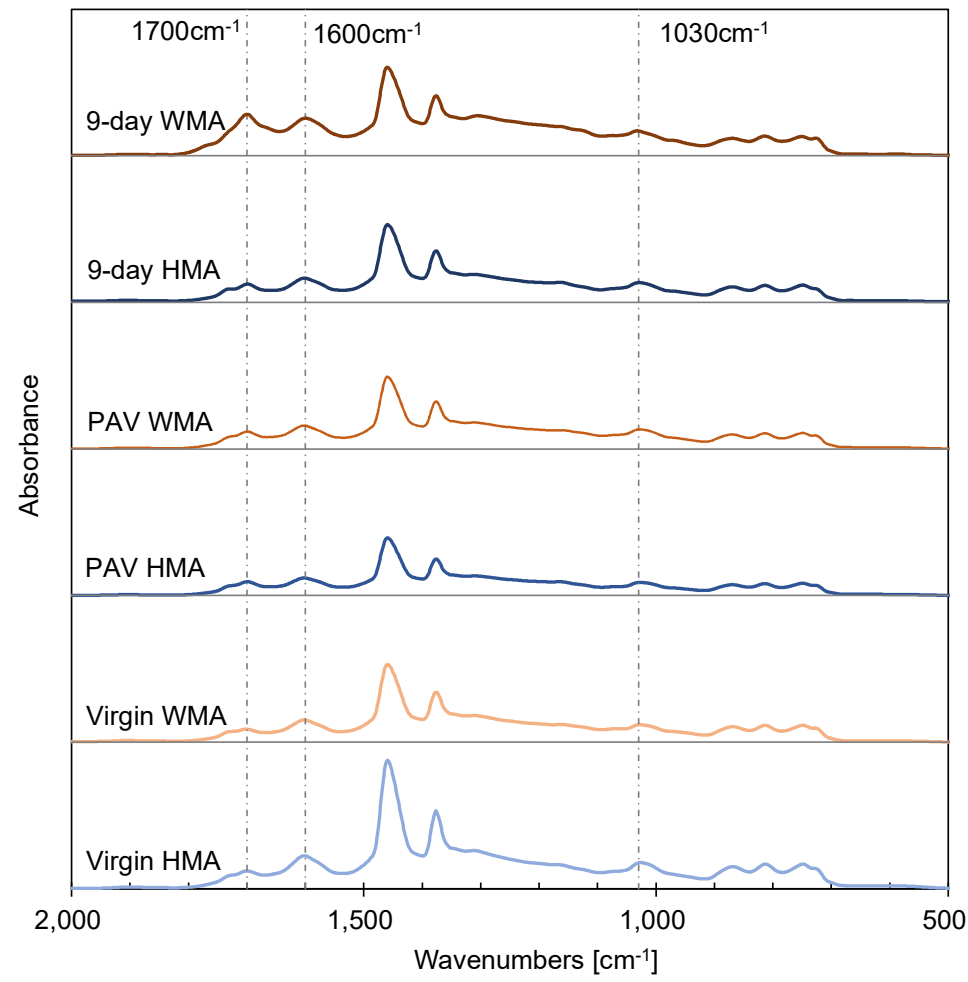

Figure 7. FTIR spectra for the WMA binders before and after ageing.

Figure 8 shows a clear evolution of ageing for four binder groups based on their CI value. The more severe the oxidation reaction carried out, the more carbonyl groups were formed. Before ageing, the binders of virgin HMA, fresh WMA, 0-day HMA, and 0-day WMA had a comparable CI value. As ageing proceeded, the CI value for the virgin HMA binder in group 1 increased linearly, from $17.8 \%$ to $39.4 \%$. However, the CI value for the fresh WMA binder in group 2 almost did not change after RTFO ageing.

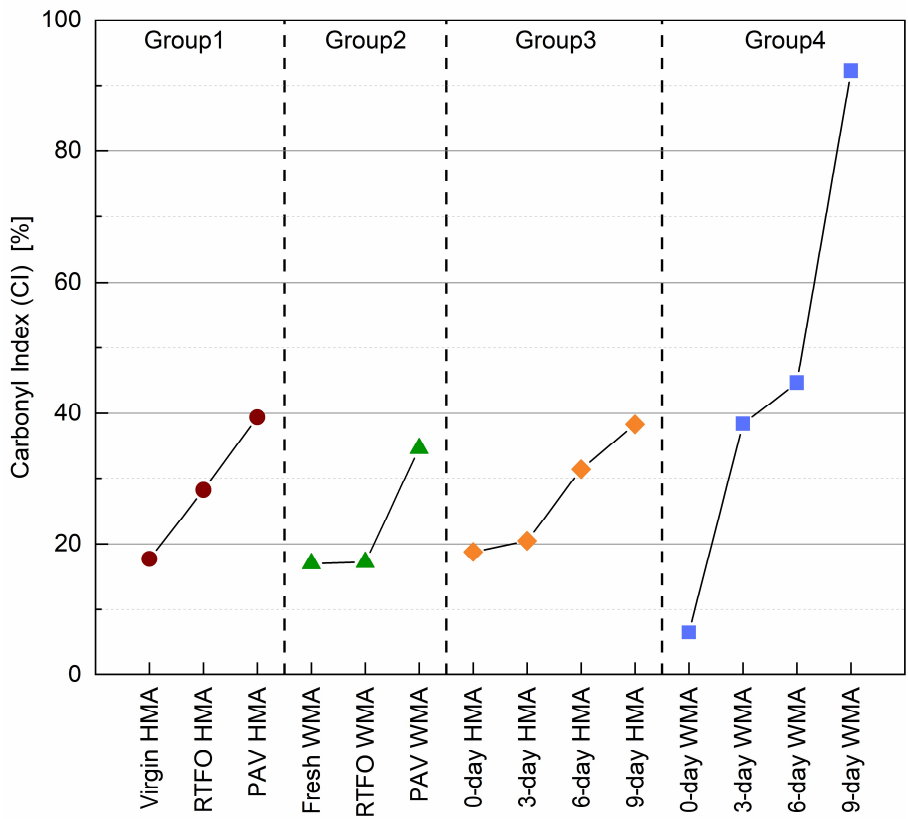

Figure 8. The carbonyl index (CI) for four binder groups before and after ageing. 
In comparison, the CI value for the PAV WMA binder in group 2 was lower than that of the PAV HMA binder in group 1. The reason could be that the addition of the warm agent increased the ageing resistance of the virgin binder. Binder group 3 underwent mixture oven ageing, and its 9-day HMA binder had a comparable CI value with that of the PAV HMA binder. However, the CI value of binders in group 4 increased rapidly as ageing proceeded, which means that the oven ageing of the foamed binder in the mixture accelerated with a water content of $5.5 \%$.

\subsection{GPC}

Figure 9 shows a typical example of GPC curves for the binders in group 4 . There are mainly three peaks from left to right for each curve, representing LMS, MMS, and SMS parts. For the binder from 0-day WMA to 9-day WMA, three main peaks shift to the left. The width of the first peak represents the part of LMS increased, which means that the bituminous molecules were transformed from small to large ones due to ageing.

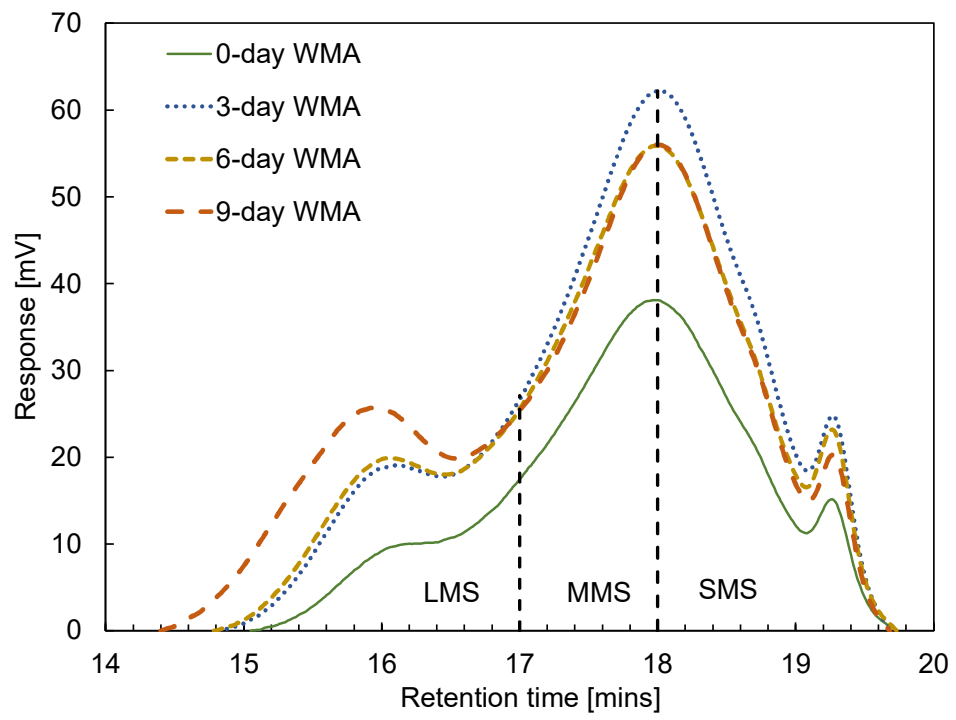

Figure 9. GPC curves for the binders of group 4.

Figure 10 shows the change in the component proportion of each binder due to ageing. In general, the SMS proportion decreased, but that of the LMS increased as ageing proceeded. However, the changing trend in the MMS proportion depended on the binder group and ageing condition. Volatilisation and oxidation simultaneously occurred when preparing fresh WMA, 0-day HMA, and 0-day WMA binders. Therefore, they had a lower SMS and a lower LMS than the virgin HMA binder. The LMS component increased sharply for binder group 2, and three components became comparable after PAV ageing. Three components for group 3 had a slight change as ageing proceeded. Even after the 9-day oven ageing, the LMS component only increased by $9.3 \%$. This means that the HMA mixture had better ageing resistance. For group 4, both SMS and MMS decreased, and the LMS dramatically increased to $45.8 \%$. 


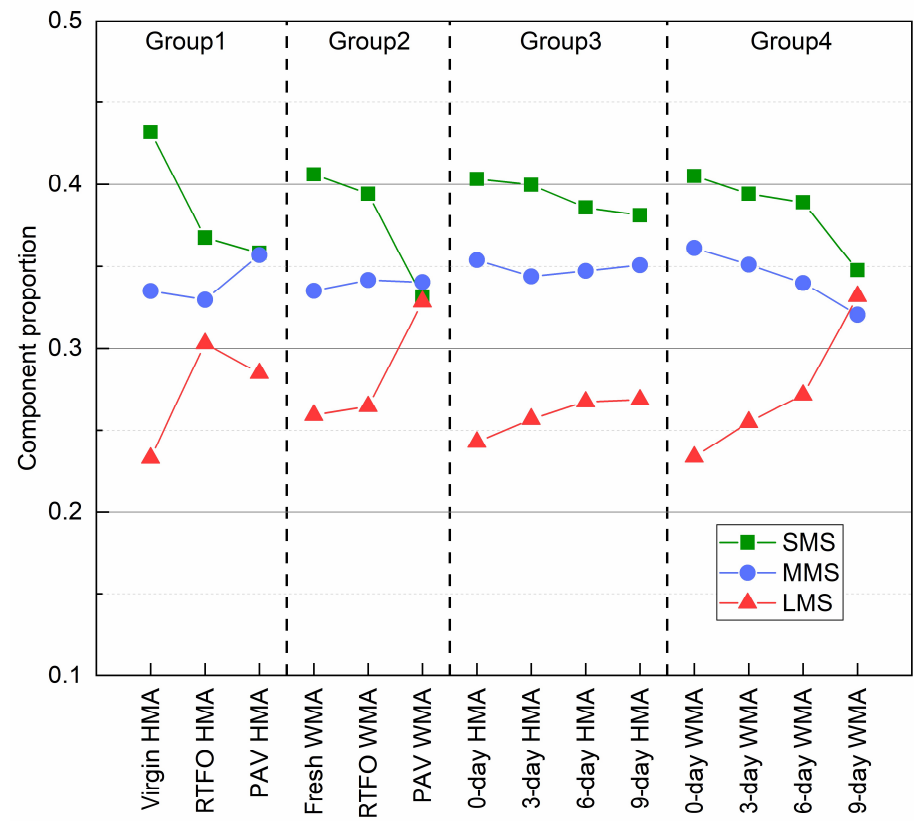

Figure 10. Components proportion (SMS, MMS, and LMS) of the binder before and after ageing according to the GPC curve.

\subsection{The Four Fractions}

Figure 11a shows the change in four fractions of all binders as a function of ageing. After PAV ageing, the aromatics content for the virgin binder in group 1 decreased by $10 \%$, but its asphaltenes content increased by almost the same percentage. However, its saturates and resins contents were relatively stable. It means that after PAV ageing, the transformation of aromatics to resins equalled resins to asphaltenes. After the same ageing mode (RTFOT or PAV), the contents of resins and asphaltenes in group 2 were lower than those in group 1 . This means that the addition of the warm agent improved the ageing resistance of the virgin binder.

For group 3, its asphaltenes content increased slightly as oven ageing proceeded (Figure 11b). However, the changing trend for aromatics and resins fluctuated. For example, there was a decrease in resins but an increase in aromatics after the 6-day oven ageing. The reason could be that decomposition occurred on resins [26]. For group 4, there was a clear changing trend for each fraction. After 9-day oven ageing, aromatic and resins were continuously transformed towards asphaltenes, which reached $35.2 \%$; the value of asphaltene confirmed its considerable ageing condition.

The colloid index (Ic) was employed to describe ageing behaviour. It is defined as the ratio of the dispersed component to the flocculating component as follows:

$$
\text { Ic }=(\text { Aromatics }+ \text { Resins }) /(\text { Saturates }+ \text { Asphaltenes })
$$

A higher Ic value means a lower ageing degree of binder or better colloidal stability. As Figure 12 shows, the Ic value of fresh WMA and RTFO WMA was slightly higher than those of virgin HMA and RTFO HMA. This result means that the addition of a warm agent improved its short-time ageing resistance. The Ic value of 0-day HMA was lower than that of virgin HMA, which means that the foaming process destroyed the colloidal performance of the binder. However, its Ic value changed slightly from 0-day to 9-day oven ageing. The Ic value for group 4 decreased sharply and reached a minimum of 0.93 after 9-day oven ageing. This means that the WMA mixture had a worse ageing behaviour than the HMA mixture in this study. 


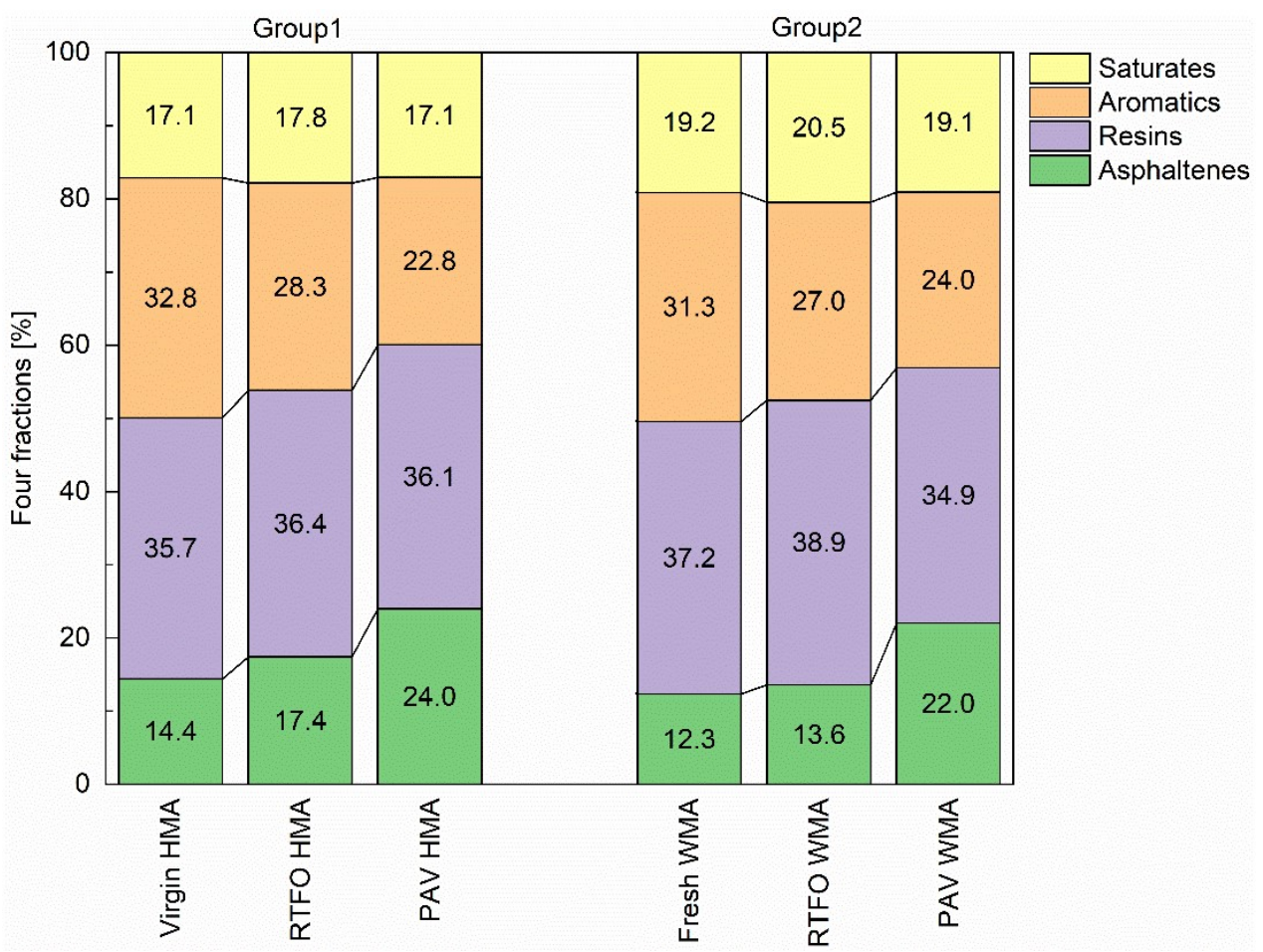

(a)
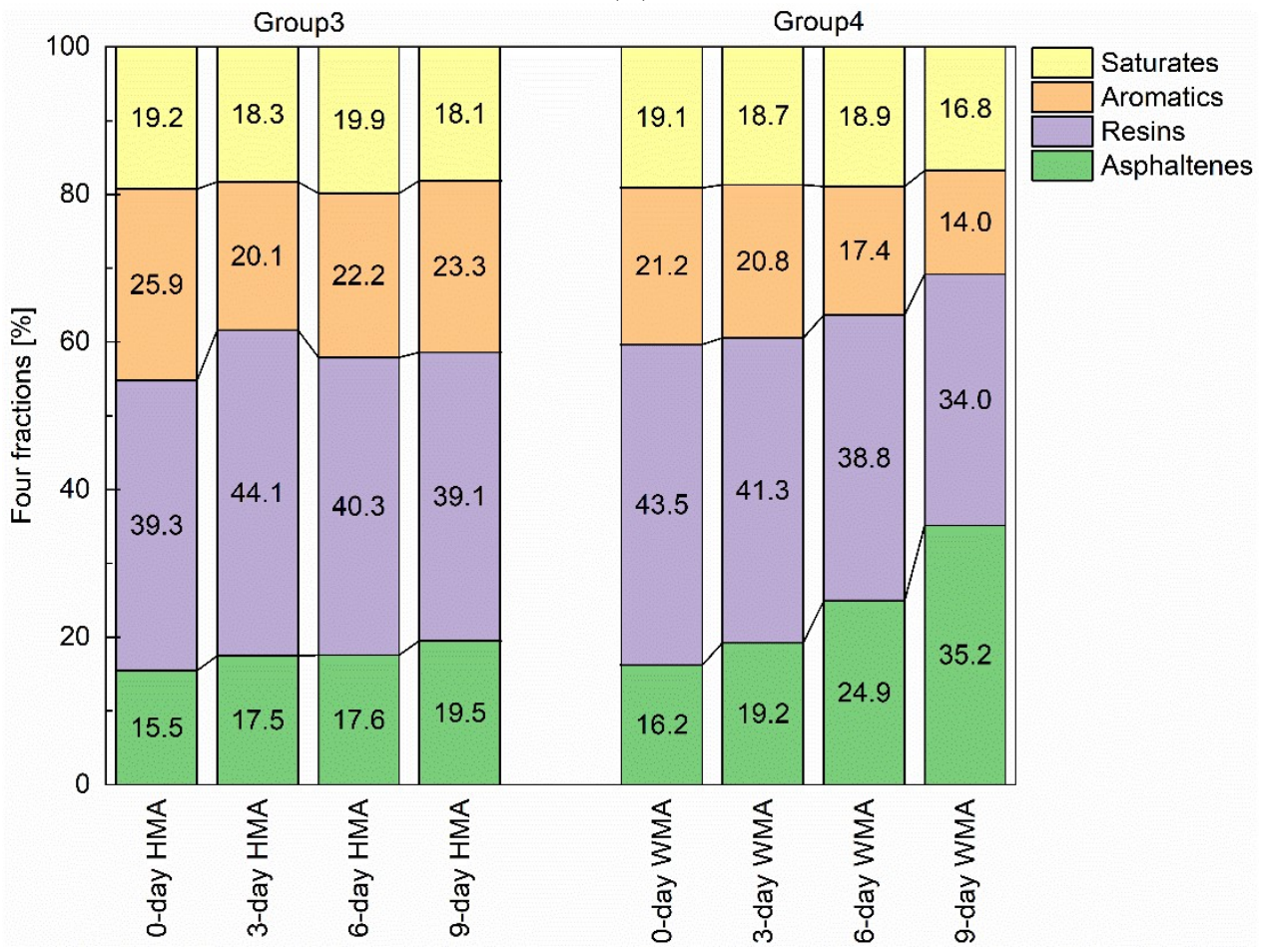

(b)

Figure 11. Change in four fractions of all binder as a function of ageing. (a) for groups 1, 2, and (b) for groups 3 and 4 . 


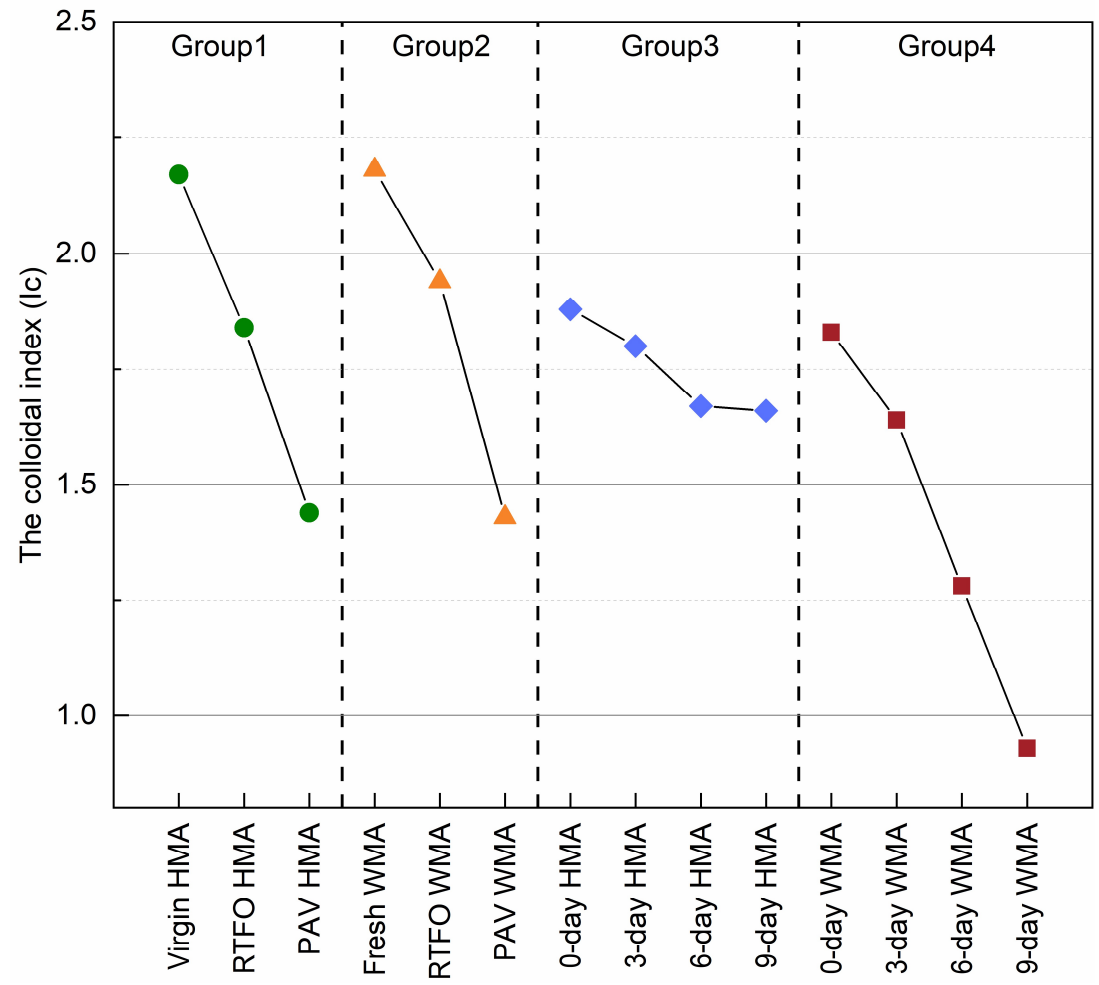

Figure 12. Change in Ic of all binder as the function of ageing.

A correlation ( $\mathrm{r}$ ) analysis was performed between the viscosity and chemical properties of all 14 binder samples. The results indicated that the viscosity at $60{ }^{\circ} \mathrm{C}$ had the highest correlation with the asphaltene content $(\mathrm{r}=0.81)$, followed by the colloid index $(\mathrm{r}=0.78)$ and carbonyl content $(\mathrm{r}=0.74)$ and the LMS area $(\mathrm{r}=0.69)$.

\section{Conclusions}

Based on the rheological and chemical results, the following conclusions were drawn:

(1) The warm agent reduced the viscosity of bitumen and its shear-thinning behaviour. The dual effect of the used warm agent and foaming water reduced the viscosity of bitumen by $34.5 \%$ at $120{ }^{\circ} \mathrm{C}$. It can, therefore, effectively reduce the rolling temperature of its corresponding asphalt mixture, improving its compaction efficiency and saving energy consumption.

(2) The viscosity of the binder, as an indicator of the evolution of ageing with time, had the highest correlation with the asphaltene content, followed by the colloid index, the carbonyl content, and the LMS area. Such value with high correlation can be used as one of the standards to quickly judge the degree of asphalt ageing.

(3) Compared with HMA, the warm agent improved the ageing resistance of the binder. However, the high foaming water content of $5.5 \%$ deteriorated this property during oven ageing on the mixture. The reason could be that a large expansion ratio makes the bitumen film thinner and more easily reachable by oxygen and then resulted in more oxidation. Based on the results and previous experience, less than $2 \%$ or warm agent and foaming water is recommended as the optimal ratio for foamed WMAs.

Author Contributions: Conceptualisation, A.H.; methodology, G.L.; software, V.M.; formal analysis, S.C.S.; investigation, T.C.; resources, H.H.; writing—original draft preparation, A.H.; writing—review and editing, G.L. All authors have read and agreed to the published version of the manuscript.

Funding: This research was funded by the Hainan Provincial Joint Project of Sanya Yazhou Bay Science and Technology City, Grant No.: 520LH016, the National Natural Science Foundation of 
China, Grant No.: 52068061, the Open Fund Project of State Key Laboratory of Silicate Materials for Architectures (Wuhan University of Technology), Grant No.: YSJJ2020-09.

Institutional Review Board Statement: Not applicable.

Informed Consent Statement: Not applicable.

Data Availability Statement: The reported results of supporting data can be found on the Web of Science.

Acknowledgments: V.M. and S.C.S. thank Cerema and Université Gustave Eiffel for allowing the creation of the joint research team entitled "Équipe de Recherche Commune sur les Matériaux pour une Construction Durable (ERC MCD)", within which these research works were carried out.

Conflicts of Interest: The authors declare no conflict of interest.

\section{References}

1. Vaitkus, A.; Vorobjovas, V.; Iliute, L. In The research on the use of warm mix asphalt for asphalt Pavement structures. In Proceedings of the XXVII International Baltic Road Conference, Riga, Latvia, 24-26 August 2009.

2. Wu, S.; Tahri, O.; Shen, S.; Zhang, W.; Muhunthan, B. Environmental impact evaluation and long-term rutting resistance performance of warm mix asphalt technologies. J. Clean. Prod. 2021, 278, 123938. [CrossRef]

3. Fakhri, M.; Rahimzadeh Mottahed, A. Improving moisture and fracture resistance of warm mix asphalt containing RAP and nanoclay additive. Constr. Build. Mater. 2021, 272, 121900. [CrossRef]

4. Rubio, M.C.; Martínez, G.; Baena, L.; Moreno, F. Warm mix asphalt: An overview. J. Clean. Prod. 2012, 24, 76-84. [CrossRef]

5. Caputo, P.; Abe, A.A.; Loise, V.; Porto, M.; Calandra, P.; Angelico, R.; Rossi, C.O. The Role of Additives in Warm Mix Asphalt Technology: An Insight into Their Mechanisms of Improving an Emerging Technology. Nanomaterials 2020, 10, 1202. [CrossRef]

6. Trujillo, P. Long Term Aging Study of WMA Binder. Master Thesis, University of Texas, Austin, TX, USA, 2011.

7. Gandhi, T.; Akisetty, C.; Amirkhanian, S. Laboratory evaluation of warm asphalt binder aging characteristics. Int. J. Pavement Eng. 2009, 10, 353-359. [CrossRef]

8. Xiao, F.P.; Amirkhanian, S.N.; Zhang, R.G. Influence of Short-Term Aging on Rheological Characteristics of Non-Foaming WMA Binders. J. Perform. Constr. Facil. 2012, 26, 145-152. [CrossRef]

9. Banerjee, A.; Smit, A.D.; Prozzi, J.A. The effect of long-term aging on the rheology of warm mix asphalt binders. Fuel 2012, 97, 603-611. [CrossRef]

10. Arshad, A.K.; Shaffie, E.; Ismail, F.; Hashim, W.; Mustapa, N.S.F. Iop In Warm Mix Asphalt Surfacing Performance for Different Aggregate Gradations with Cecabase RT Additive. In Proceedings of the 5th International Conference on Civil and Environmental Engineering for Sustainability (IConCEES), Senai, Malaysia, 19-20 December 2019; Iop Publishing Ltd.: Senai, Malaysia, 2020.

11. Dokandari, P.A.; Topal, A. Effects of Warm Mix Asphalt Additives on Aging Characteristics of Bituminous Mixtures. Period. Polytech.-Civ. Eng. 2015, 59, 475-486. [CrossRef]

12. Hasan, M.R.M.; Goh, S.W.; You, Z.P. Comparative study on the properties of WMA mixture using foamed admixture and free water system. Constr. Build. Mater. 2013, 48, 45-50. [CrossRef]

13. Safaei, F.; Lee, J.S.; do Nascimento, L.A.H.; Hintz, C.; Kim, Y.R. Implications of warm-mix asphalt on long-term oxidative ageing and fatigue performance of asphalt binders and mixtures. Road Mater. Pavement Des. 2014, 15, 45-61. [CrossRef]

14. Abbas, A.R.; Nazzal, M.; Kaya, S.; Akinbowale, S.; Subedi, B.; Arefin, M.S.; Abu Qtaish, L. Effect of Aging on Foamed Warm Mix Asphalt Produced by Water Injection. J. Mater. Civ. Eng. 2016, 28. [CrossRef]

15. Hamzah, M.O.; Jamshidi, A.; Shahadan, Z. Evaluation of the potential of Sasobit (R) to reduce required heat energy and $\mathrm{CO}_{2}$ emission in the asphalt industry. J. Clean. Prod. 2010, 18, 1859-1865. [CrossRef]

16. Chen, Z.W.; Wu, S.P.; Xiao, Y.; Zeng, W.B.; Yi, M.W.; Wan, J.M. Effect of hydration and silicone resin on Basic Oxygen Furnace slag and its asphalt mixture. J. Clean. Prod. 2016, 112, 392-400. [CrossRef]

17. Pan, P.; Wu, S.P.; Xiao, Y.; Liu, G. A review on hydronic asphalt pavement for energy harvesting and snow melting. Renew. Sustain. Energy Rev. 2015, 48, 624-634. [CrossRef]

18. Zhang, X.S.; Xiao, Y.; Long, Y.S.; Chen, Z.W.; Cui, P.Q.; Wu, R.; Chang, X.W. VOCs reduction in bitumen binder with optimally designed $\mathrm{Ca}(\mathrm{OH})(2)$-incorporated zeolite. Construct. Build. Mater. 2021, 279. [CrossRef]

19. Raab, C.; Camargo, I.; Partl, M.N. Ageing and performance of warm mix asphalt pavements. J. Traffic Transp. Eng. 2017, 4, 388-394. [CrossRef]

20. Some, S.C.; Barthelemy, J.F.; Mouillet, V.; Hammoum, F. Effect of ageing kinetics on the rheological properties of bituminous binders and mixes: Experimental study and multi-scale modeling. In Proceedings of the RILEM International Symposium on Bituminous Materials, ISBM, Lyon, France, 14-16 December 2020; p. 6.

21. Xue, Y.J.; Wei, X.T.; Zhao, H.; Wang, T.; Xiao, Y. Interaction of spent FCC catalyst and asphalt binder: Rheological properties, emission of VOCs and immobilization of metals. J. Clean. Product. 2020, 259. [CrossRef]

22. Kim, S.; Lee, S.H.; Kwon, O.; Han, J.Y.; Kim, Y.S.; Kim, K.W. Estimation of service-life reduction of asphalt pavement due to short-term ageing measured by GPC from asphalt mixture. Road Mater. Pavement Des. 2016, 17, 153-167. [CrossRef] 
23. Kim, M.; Cooper, J.; Mohammad, L.; Baumgardner, G.L. Asphalt Mixtures Containing RAS and/or RAP: Relationships Amongst Binder Composition Analysis and Mixture Low Temperature Cracking Performance. Road Mater. Pavement Des. 2017, 18, 209-234. [CrossRef]

24. Chang, X.W.; Zhang, R.H.; Xiao, Y.; Chen, X.Y.; Zhang, X.S.; Liu, G. Mapping of publications on asphalt pavement and bitumen materials: A bibliometric review. Construc. Build. Mater. 2020, 234, 117370. [CrossRef]

25. Dong, F.; Yu, X.; Liang, X.; Ding, G.; Wei, J. Influence of foaming water and aging process on the properties of foamed asphalt. Constr. Build. Mater. 2017, 153, 866-874. [CrossRef]

26. Yu, X.; Zaumanis, M.; dos Santos, S.; Poulikakos, L.D. Rheological, microscopic, and chemical characterization of the rejuvenating effect on asphalt binders. Fuel 2014, 135, 162-171. [CrossRef] 